\title{
Análisis del fallo del Tribunal Constitucional sobre la píldora del día después*
}

Este comentario, junto a los documentos que analiza, está disponible en www.anuariocdh.uchile.cl
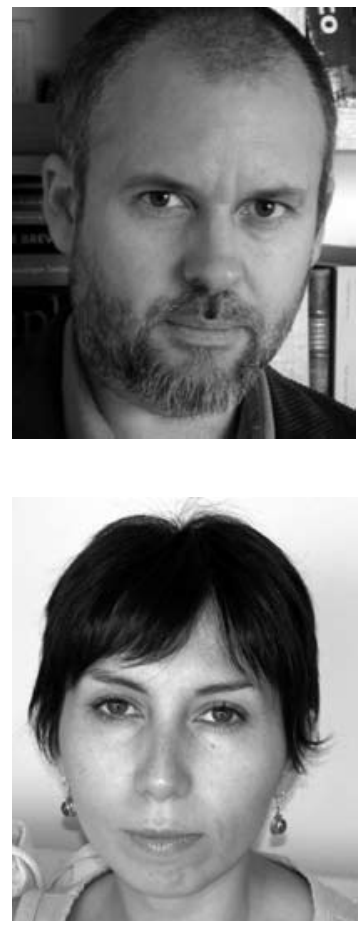

\section{Andrés Bordalí Salamanca}

Abogado, Licenciado en Derecho por la U. de Chile; Doctor en Derecho por la Universidad de Valladolid, España; Director Instituto de Derecho Público U. Austral de Chile; Director Revista de Derecho U. Austral de Chile; Profesor de Derecho Procesal (Parte General) y Derecho Procesal Constitucional.

abordali@uach.cl

\section{Yanira Zúñiga Añazco}

Abogada, Doctora en Derecho, Profesora Universidad Austral de Chile. Instituto de Derecho Público, Facultad de Ciencias Jurídicas y Sociales, Campus Isla Teja, Valdivia, Chile.

yzuniga@uach.cl

\section{RESUMEN}

Los autores analizan críticamente la sentencia del Tribunal Constitucional relativa a la anticoncepción de emergencia, centrando su análisis, por una parte, en el rol del tribunal en el juego de poderes democráticos, y por otra, en la omisión de las mujeres como un sujeto de derechos relevante en la sentencia.

\section{El rol del Tribunal Constitucional en el sistema de poderes constitucionales}

Se ha discutido en este último tiempo el impacto que la reforma constitucional de 2005 ha significado para el diseño institucional democrático chileno. Y ha sido con el fallo del Tribunal

\footnotetext{
* Los comentarios relativos a la legitimidad y competencia del Tribunal Constitucional para fallar la impugnación del decreto referido a la denominada "píldora del día después" corresponden a Andrés Bordalí Salamanca, mientras que el análisis del fallo en lo relativo a los derechos sexuales y reproductivos de las mujeres y la perspectiva de género corresponde a Yanira Zúñiga Añazco.
} 
Constitucional (TC) rol 740 de fecha 18 de abril de 2008 que recayó sobre el Decreto Supremo $N^{\circ} 48$ del Ministerio de Salud "Normas nacionales sobre regulación de la fertilidad" o, más resumidamente, sobre la "píldora del día después", donde se produjo un punto de inflexión, generándose una airada crítica política y ciudadana sobre el rol que cumple nuestro Tribunal Constitucional en el sistema de poderes constitucionales, como asimismo sobre el adecuado reconocimiento de la autonomía reproductiva de la mujer.

La repercusión pública del último fallo del Tribunal Constitucional sobre la "píldora del día después" demuestra que la crítica feminista, sintetizada en el eslogan lo personal es político, encierra bastante más que una consigna provocadora. No es de extrañar entonces que después del fallo sobre la píldora se presentara en el Congreso Nacional un proyecto de reforma constitucional el 19 de mayo de 2008 (Boletín 5881-07) que establece la posibilidad de convocar a referéndum por el Presidente de la República o por el 1,5\% de los ciudadanos inscritos en los registros electorales para que se revoque una sentencia del Tribunal Constitucional. Dentro de los fundamentos de dicho proyecto se cita expresamente la situación del fallo de la "píldora del día después" como expresión de supresión de la voluntad popular por parte de un tribunal de justicia que carece de legitimidad democrática.

Posteriormente, con fecha 16 de octubre de 2008, se presentó un proyecto de reforma a la Ley Orgánica Constitucional del Tribunal Constitucional (Boletín 6163-07), por el que se pretende ampliar las causales de implicancia de los ministros del Tribunal Constitucional y los sujetos legitimados para hacerla valer. Esta propuesta legislativa puede vincularse con la situación de inhabilidad del Ministro Raúl Bertelsen para fallar esta causa. Dicho Ministro, en un informe en Derecho presentado en un proceso tramitado ante la judicatura ordinaria con anterioridad al que nos estamos refiriendo en estas páginas, y donde se discutió sobre la validez constitucional de la utilización de la "píldora del día después", había manifestado su opinión jurídica como jurista en el sentido de que tal fármaco era claramente abortivo ${ }^{1}$.

Finalmente, pocos días antes de conocerse el fallo del Tribunal Constitucional sobre la "píldora del día después", con fecha 9 de abril de 2008 se presentó en el Congreso Nacional un proyecto de reforma constitucional (Boletín 5803-07) por el que se pretende incorporar a los ministros del Tribunal Constitucional como sujetos pasivos de la acusación constitucional que resuelve en definitiva el Senado a requerimiento de un grupo de diputados y por la que algunos personeros públicos pueden ser destituidos de su cargo.

Ninguno de estos proyectos al día de hoy ha sido aprobado, pero todos ellos son una manifestación palmaria de la airada reacción que este fallo causó en algunos sectores del país.

La crítica al actuar de los tribunales constitucionales no es nueva. El argumento es el mismo de siempre. La decisión del Tribunal Constitucional deja sin efecto la decisión adoptada por los órganos representativos de la voluntad popular, sea el Legislativo o el Ejecutivo. Se retoma así la tesis de Carl Schmitt esbozada a principios del siglo XX. Para Schmitt ${ }^{2}$ el problema de introducir un tribunal constitucional consiste en trasladar la política a la justicia o, lo que es lo mismo, comporta una politización de la justicia. Esa traslapación de funciones estatales se produce, según Schmitt, porque los conflictos constitucionales son dudosos e inciertos, debido fundamentalmente a la necesaria imperfección o vaguedad de toda Constitución escrita. De este modo, un juez

1 Lo que se puso en el debate era si en este caso le era aplicable la causal del artículo 19 de la Ley orgánica constitucional del Tribunal Constitucional (LOCTC), referida al "hecho de haber emitido opinión con publicidad o dictamen sobre el asunto concreto actualmente sometido a conocimiento del Tribunal". El Tribunal Constitucional, por mayoría de votos, consideró que no le afectaba la causal de inhabilitación.

2 Cfr. SCHMITT, C., La defensa de la Constitución. Madrid, Tecnos, 1983, p. 57. 
que pretenda defender la Constitución termina siempre por crear una norma y no por aplicarla, como corresponde a la función del juez en un Estado de Derecho. Esto ocurre debido a que en materia constitucional no puede producirse ningún procedimiento de subsunción ya que no hay un supuesto fáctico normativo suficientemente predeterminado.

Fernando Atria $^{3}$, entre nosotros, presenta las relaciones entre parlamento y judicatura constitucional como una pugna entre lo que decidimos nosotros y lo que decide una parte de nosotros, es decir, una facción de nosotros. Este problema puede trasladarse a las relaciones entre el Ejecutivo y el Tribunal Constitucional. El argumento es el siguiente: respecto a los órganos políticos dotados de legitimidad democrática se configura el ideal político de autogobierno, por lo que se puede entender que las decisiones de esos órganos son "nuestras decisiones". Por el contrario, cuando los jueces hacen una aplicación directa de la Constitución, esa decisión ya no es "nuestra" sino de un parte de nosotros y como tal es facciosa.

\section{Acerca de la competencia del Tribunal Constitucional}

Dejando por ahora de lado esta crítica a la aplicación judicial de los preceptos constitucionales que la inmensa mayoría de la doctrina nacional y comparada ha dejado algo abandonada, debemos indagar sobre si ha sido legítima la decisión del Tribunal Constitucional en el caso de la "píldora del día después", lo que explicaría tanto revuelo. Al respecto, hay que señalar que la competencia del Tribunal Constitucional para haber conocido y fallado en la causa que analizamos está reconocida constitucionalmente en el artículo 93 No 16 CPR, el cual señala que son atribuciones del Tribunal Constitucional "[r]esolver sobre la constitucionalidad de los decretos supremos, cualquiera sea el vicio invocado, incluyendo aquellos que fueren dictados en el ejercicio de la potestad reglamentaria autónoma del Presidente de la República cuando se refieran a materias que pudieran estar reservadas a la ley por mandato del artículo 63". En este sentido, el fallo sobre la "píldora del día después" se enmarca dentro del cuadro de las competencias constitucionalmente definidas para este tribunal.

Sin embargo, al afirmar que el artículo 93 № 16 CPR confiere la competencia al Tribunal Constitucional para declarar la inconstitucionalidad de un decreto supremo del Presidente de la República, en este caso un decreto de ejecución por razones de fondo, estamos dejando de lado la extensa polémica que ha existido en nuestro Derecho Público sobre el reconocimiento de estas competencias, al menos antes de la reforma constitucional de 2005.

Antes de la reforma constitucional de 2005 un sector de la doctrina consideró que el control de constitucionalidad de los decretos supremos sólo podía referirse a razones de forma, ya que el control de fondo era resorte de la Contraloría General de la República. En otros casos se entendió que el vicio consistía sólo en dictar un decreto promulgatorio inconstitucional. Otro sector de la doctrina y sobre todo el propio Tribunal Constitucional entendían que el control de constitucionalidad de los decretos supremos que le encomendaba el artículo 82 números $5^{\circ}$ y $12^{\circ} \mathrm{CPR}$ era amplio, lo que equivale a decir que éste era procedente tanto respecto de decretos supremos de ejecución y aquellos autónomos, así como por vicios de fondo o de forma 4 .

3 Cfr. ATRIA, F. Seguridad jurídica y derechos fundamentales: Sobre predecibilidad y autogobierno. En BORDALÍ, A. (coord.). Justicia constitucional y derechos fundamentales. Santiago de Chile, Lexis Nexis, 2006, pp. 9 y 10.

4 Para un estudio de la discusión doctrinaria y jurisprudencial del control de constitucionalidad de los actos del Presidente de la República por parte del Tribunal Constitucional antes de la reforma constitucional de 2005, véase CAZOR, K. La sumisión a derecho de los actos y disposiciones del Presidente de la República. Tomo II. Santiago de Chile. Universidad Central de Chile, 2002, pp. 123 y ss. 
Sin embargo, la reforma constitucional de 2005, en nuestro concepto, despejó todas estas dudas, toda vez que existen dos disposiciones que se refieren con absoluta nitidez y amplitud al control de los actos del Ejecutivo por parte del Tribunal Constitucional. Son los numerales $9^{\circ}$ y $16^{\circ}$ del artículo 93 Constitución Política de la República (CPR). La clave está en el numeral $16^{\circ}$ que se refiere al control de los decretos supremos, "cualquiera sea el vicio invocado", esto es, por vicios de fondo o de forma; y luego está la expresión "incluyendo aquellos [decretos supremos] que fueren dictados en el ejercicio de la potestad reglamentaria autónoma del Presidente de la República...", lo que deja entrever que los decretos supremos de ejecución también pueden ser objeto de control. En la especie, el Decreto Supremo No 48 del Ministerio de Salud corresponde a la ejecución del Decreto con Fuerza de Ley № 1, que es la Ley Orgánica Constitucional del Ministerio de Salud.

Luego, la crítica al fallo del Tribunal Constitucional en el caso de la "píldora del día después" no puede referirse a si éste tenía o no la competencia para conocer y resolver el asunto. Es claro que la Constitución se la confiere. Ello no impide, ciertamente, asumir las críticas que formularemos al contenido del fallo desde el punto de vista de la argumentación constitucional, así como tampoco impide criticar la decisión de la mayoría parlamentaria que reformó la Constitución de 1980 en el mes de agosto de 2005, por haber conferido tan vastas competencias de control de constitucionalidad al Tribunal Constitucional. Muchos de esos parlamentarios, luego de aprobar la reforma, criticaron duramente al Tribunal Constitucional por la decisión que adoptó en este caso, en circunstancias que ellos mismos le confirieron el marco atributivo para arribar a decisiones como éstas. Es criticable que los parlamentarios, en vez de repensar la situación de conferir potestades de control de constitucionalidad sobre decretos supremos al Tribunal Constitucional, hayan profundizado ese control permitiendo entrar al fondo del acto administrativo cuestionado.

La mayoría de los países que cuentan con un control de constitucionalidad radicado en un Tribunal Constitucional, salvo Austria, no incluyen dentro de sus competencias a los actos administrativos, limitando por lo general el control a las leyes. El control sobre los actos administrativos se atribuye normalmente a los tribunales de justicia que conocen del contencioso administrativo. Es que en el control jurisdiccional de los actos de los poderes del Estado debería siempre considerarse la no acumulación en un solo órgano de tantas competencias, de modo de no convertirlo en un "superpoder", como es el caso del Tribunal Constitucional chileno.

La experiencia nacional en estos últimos dieciocho años de renovada vida democrática demuestra que la impugnación de los decretos supremos del Presidente de la República ha sido realizada principalmente por la oposición política, con lo que en el control de estos actos, lejos de discutirse si afectan o no los derechos o intereses de ciudadanos concretos, se asoma como un mero instrumento de lucha política entre gobierno y oposición. Hay que señalar que en Chile los decretos supremos vigentes sólo pueden ser impugnados ante el Tribunal Constitucional por las Cámaras o por una cuarta parte de los miembros en ejercicio de dichas Cámaras, pero los particulares están excluidos.

En un plano de lege ferenda, el Tribunal Constitucional sólo debería controlar, formalmente, que un decreto supremo no invada el dominio legal en el caso de los decretos supremos autónomos, y que no se aparten del acto legislativo habilitante en el caso de los decretos de ejecución. Si el decreto supremo, en lo sustancial, vulnera un derecho o interés de carácter constitucional de uno o más sujetos concretos, deberían los tribunales que conocen del contencioso administrativo brindar la tutela a esos sujetos y sólo a requerimiento de éstos. Sólo así puede encauzarse el control jurisdiccional de los actos del Presidente de la República dentro de equilibrios razonables para la gobernabilidad democrática y el Estado de Derecho. 


\section{La consideración de la mujer como sujeto de derechos y la interpretación constitucional}

El fallo del TC sobre la píldora del día después adolece de múltiples defectos desde el punto de vista de los criterios de la interpretación constitucional que podrían comentarse latamente por separado. Sin embargo, preferiremos una lectura más bien panorámica de dichos defectos.

Una característica transversal de la sentencia es la falta de consideración de las mujeres como sujetos de derechos. La negación de la subjetividad femenina parece correlacionarse con la afirmación de la subjetividad del nasciturus, a cuya defensa argumental el TC dedica, en cambio, una parte importante de los pasajes del fallo. Téngase en mente, no obstante, que desde un punto de vista lógico no hay contradicción alguna en afirmar la subjetividad de las mujeres y la del nasciturus a la vez. Claro está, que tal aproximación hubiera implicado calificar el asunto planteado por los recurrentes como un problema de colisión de derechos de distinto titular y no -como termina haciendo el TC siguiendo la tesis de los recurrentes- como un problema de limitación de derechos de un solo sujeto, a saber, el derecho a la vida del feto. De más está decir que el recorrido argumental es más complejo en el primero que en el segundo caso.

Con todo, en este último supuesto también se deben satisfacer ciertas exigencias de fundamentación sintetizadas en el llamado principio de proporcionalidad. Dicho principio supone que toda medida de restricción legítima de derechos debe respetar estrictamente los subprincipios de idoneidad, necesidad y de proporcionalidad. En consecuencia, sólo si una medida no se acomoda a estos tres subprincipios, ésta puede declararse inconstitucional. Lo anterior no es más que el reflejo de la relatividad de los derechos fundamentales, es decir, del hecho de que éstos coexistan con otros intereses o bienes constitucionalmente protegidos con los que pueden entrar en conflicto. De ahí que cuando un tribunal ejerce el control de constitucionalidad de una medida restrictiva de derechos fundamentales no puede contentarse con interpretar el contenido del derecho eventualmente afectado (cuestión que, en sí misma involucra otros criterios interpretativos como, por ejemplo, la noción del contenido esencial) y debe, además, examinar tanto el costo de la aplicación de la medida impugnada como también el costo de su no aplicación en relación con el adecuado cumplimiento de los fines que ésta persigue. Por tanto, en el caso de la píldora del día después, incluso si el TC entendiera que no había una colisión de derechos, debiera haber ponderado el costo de una incierta afectación de la vida del embrión versus el costo de la reducción de la eficacia de una política de prevención del embarazo adolescente o de una intervención estatal destinada a disminuir los efectos negativos del delito de violación. Lo anterior, partiendo de la base de que ambas medidas persiguen finalidades que pueden estimarse constitucionalmente legítimas.

No obstante, en el fallo en cuestión el TC ni consideró que hubiese una colisión de derechos, ni aplicó el criterio de proporcionalidad para juzgar si la restricción presuntamente impuesta por la norma administrativa analizada, era constitucionalmente aceptable. Al contrario, el TC a través de su teoría de la "duda razonable" concluye que basta la amenaza de afectación (o más bien, la simple apariencia) para que la medida restrictiva devenga inconstitucional. Y esta tesis se sustenta en una cadena argumentativa a la que le bastan tres eslabones, a saber: a) la premisa de que el embrión es persona; b) la afirmación de que en tanto persona, éste tiene derecho a la vida; y c) que dicha titularidad implica la inconstitucionalidad de toda norma que amenace su gestación.

Pese a su simpleza, esta forma de encarar el problema planteado ante el tribunal parece tener un poder de persuasión inusitado. Desde luego, es compartida por los parlamentarios que plantearon el requerimiento de inconstitucionalidad y también por los diputados que en el año 2005 se negaron a tramitar un proyecto de ley de despenalización del aborto por considerar que se requería previamente modificar el artículo 19 № 1 que, como es sabido, no prohíbe el aborto sino que 
sólo encomienda al legislador proteger la vida del que está por nacer. Así, el poder de persuasión de esta argumentación no descansa ni en su corrección lógica, ni tampoco en su apego a los procedimientos argumentativos propuestos por la teoría jurídica para conflictos o restricciones de derechos. Por el contrario, su fuerza retórica proviene del hecho de que se construye sobre premisas ocultas que operan como autoevidentes porque corresponden a una ideología de género aún arraigada en la sociedad chilena.

\section{4. "Lo personal es político" y la ciudadanía íntima. Claves para un análisis desde el género}

Desde hace varias décadas que las teóricas feministas vienen sugiriendo que la construcción de la subjetividad femenina no está acabada y que su individuación es más aparente que real ${ }^{5}$. También desde hace tiempo que las investigaciones antropológicas han establecido que una de las bases estructurales de los sistemas patriarcales consiste en el control de la sexualidad femenina y en su instrumentalización hacia la procreación ${ }^{6}$. Ambas cuestiones confluyen de una manera palmaria en los debates relativos al contenido y alcance de los derechos sexuales y reproductivos. En efecto, a diferencia del enfoque clásico de Marshall, que postula que la ciudadanía se ha edificado a través de un proceso fragmentario pero acumulativo en que se han superpuesto las ciudadanías civil, política y social, la historia demuestra -y así lo han hecho ver las teóricas feministas- que en el caso de las mujeres la ciudadanía civil no sólo no ha precedido a la ciudadanía política y a la ciudadanía social, sino que, en cambio -como ocurre en el caso chileno-, es un terreno en el que la cimentación de la subjetividad femenina sigue siendo frágil. Para comprobar este aserto recuérdese simplemente que, a nivel comparado, las leyes que predican la capacidad completa de la mujer casada para administrar sus bienes, las que permiten que desarrolle actividades fuera del hogar sin el permiso del marido, las que reprimen la violencia doméstica o la violación conyugal, las que despenalizan el adulterio femenino o las que permiten la interrupción voluntaria del embarazo datan, en general, de la década de los 80.

El pensamiento feminista ha comenzado a teorizar a partir también de los años 80 sobre las relaciones entre lo público y lo privado. Éstas no fueron objeto de atención por parte del feminismo de la primera ola que compartía la creencia (ingenua habría que agregar a la luz de los hechos) de que la adquisición de los derechos políticos y el acceso a la educación por parte de la población femenina entrañarían una emancipación correlativa en el marco de las relaciones de familia. Su desengaño va a catalizar una nutrida problematización de la pareja binaria liberal de lo público y lo privado que, hasta hoy, aporta nuevas derivas. Curiosamente, y pese a la centralidad de esta construcción dicotómica en la teoría del derecho, la crítica feminista en esta materia ha recibido poca atención entre los juristas, lo que se traduce en que el llamado enfoque de género sea una manera relativamente novedosa (y no siempre muy valorada) de analizar las normas jurídicas.

Aun reconociendo la variedad de posiciones dentro de la teoría feminista ${ }^{7}$, las principales críticas feministas a la dicotomía liberal de lo público y lo privado apuntan a la existencia de una

5 Véase, por ejemplo, PATEMAN, C. El contrato sexual, Barcelona, Universidad Autónoma Metropolitana-Anthropos, 1995; VVAA. Genre et politique. Débats et perspectives, Paris, Gallimard, 2000; y PITCH, T. Un derecho para dos. La Construcción Jurídica de Género, Sexo y Sexualidad, Madrid, Trotta, 2003.

6 Simone de Beauvoir desarrolló esta tesis en su conocido texto El segundo Sexo. Véase más recientemente el excelente texto de la antropóloga francesa Françoise Héritier: HÉRITIER, F. Masculino/Femenino. El pensamiento de la diferencia, Barcelona, Editorial Ariel, 1996.

7 En el pensamiento feminista no existe consenso sobre la importancia de cada uno de estos elementos en lo concerniente a la socialización de género, ni sobre el rol que puede asumir el Estado a este respecto (patriarcal o emancipador), sí parece ser que la formulación contemporánea de "lo personal es político" encarna más una propuesta de reconceptualización de las relaciones entre lo privado y lo público que una invitación a prescindir de toda diferenciación entre ambas esferas. En efecto, la posición que ocupa la intimidad en el desarrollo personal de los individuos y la necesidad de un espacio 
concepción patriarcal de lo público y de la familia; al presunto carácter natural y no cultural o histórico de las desigualdades entre hombres y mujeres; a una construcción del derecho a la intimidad como límite a la acción estatal que ha permitido la reproducción de las estructuras patriarcales y que se demuestra frecuentemente falaz; la supuesta ausencia de restricciones que caracterizan el contexto en que las mujeres adoptan libremente sus decisiones y, finalmente, la concepción excluyente de la política ${ }^{8}$.

La argumentación del TC en el fallo sobre la "píldora del día después" es una muestra tangible de que buena parte de los presupuestos de la dicotomía liberal público/privado que han sido criticados por la teoría feminista subyacen a la solución que nuestros tribunales y actores jurídicos en general proveen a los asuntos ligados a la ciudadanía civil femenina y, particularmente, a lo que el feminismo ha denominado la ciudadanía íntima, es decir, los aspectos ligados a la sexualidad de las mujeres.

En efecto, la omisión absoluta que hace el TC de los derechos de las mujeres está lejos de ser casual. Al contrario, refrenda la tesis de que la promesa de interferencia no estatal reflejada en la dicotomía público/privado no sólo no se cumple estrictamente, sino que, además, se traduce en una garantía condicionada al mantenimiento de un determinado statu quo, esto es, la preservación de los roles tradicionales de género. En este esquema de distribución de roles ha sido tradicional que todas las sociedades instrumentalicen a las mujeres considerándolas un medio de satisfacción de los deseos, capacidades y derechos de otros. Como se ve, la historia es tanto un pre-texto como también un pretexto ${ }^{9}$ ya que aporta una justificación previa que dirige la reflexión y el razonamiento. Y en la medida que este "pretexto" actúa como premisa, se entiende mejor por qué en los debates nacionales relativos a los derechos sexuales y reproductivos y, especialmente aquellos que involucran la interrupción del embarazo, la protección de la vida del nasciturus ha tendido a excluir la protección de los derechos de la madre. Generalmente, esta asimetría tiende a encubrirse sobre la base de argumentaciones que generan una hipertrofia del derecho a la vida sobre la base de reputarle no sólo el derecho principal del sistema, sino-como lo hace el TC en su sentencia- de atribuirle caracteres de derecho absoluto. De ahí que no sorprenda si se adhiere a la premisa de que la mujer es sólo un medio para el desarrollo de otros sujetos y, más concretamente, un útero que sirve para el desarrollo del nasciturus, que el ejercicio de la libertad sexual y reproductiva de la mujer se conceptualice como un atentado a la vida del feto.

Indudablemente una premisa como la reseñada no es compatible con los pilares de los modernos sistemas constitucionales, puesto que infringe el principio de dignidad humana que, a su vez, exige que toda persona sea tratada como fin y no como medio. Con todo, la fuerza de la ideología de género es tal que cuando resulta cuestionada su falta de adecuación a estos lineamientos puede reconstituirse fácilmente apelando a expedientes más o menos burdos. Así ocurre, por ejemplo, cuando el argumento pro-vida antes enunciado se revela falaz por su incapacidad de explicar por qué debe preferirse la vida del no nato sobre la de la madre en los casos en que ambas entran en conflicto. Entonces surge la réplica -ya clásica en Chile- que sostiene que el avance de la medi-

privado para su desenvolvimiento sugieren que la confusión de lo público y lo privado no necesariamente suministra una respuesta satisfactoria desde el punto de vista de la protección de los intereses de las mujeres. Todavía más, la evolución del concepto de intimidad sobre la que se ha asentado de una manera importante el desarrollo jurisprudencial de los derechos sexuales y reproductivos de las mujeres demuestra que más que la supresión de esta dicotomía se requiere una imperiosa revisión de los supuestos filosóficos y jurídicos en los que las esferas pública y privada se vertebran.

8 Cfr. TURÉGANO, I. La dicotomía público/ privado y el liberalismo político de John Rawls. Doxa 24, 2001, p. 320. Vid, además, BELTRÁN, E. Público y privado: sobre feministas y liberales: argumentos en un debate acerca de los límites de lo político. Doxa 15-16 (I), 1994, pp. 389-405.

9 La expresión ha sido tomada prestada de los trabajos de Geneviève Fríase. 
cina excluye cualquier riesgo para la vida de la madre. Así, se borra de un plumazo la existencia empírica de los embarazos inviables ${ }^{10}$.

\section{Otras lecturas jurídicas al mismo problema: jurisprudencia internacional y el fallo de la Corte Constitucional de Colombia}

Desde una perspectiva de género, entonces, puede entenderse mejor por qué el TC omite en su sentencia tanto los derechos fundamentales que la propia Constitución chilena atribuye a los individuos, incluidas las mujeres, como aquellos otros que están expresamente previstos en tratados internacionales aplicables al efecto. En la reinterpretación que el TC realiza del esqueleto iusfundamental de nuestra Carta se prescinde del ya mencionado principio de dignidad humana (arts. 1 y 5 de la CPR), del derecho a la protección de la vida privada (19 № 4), del derecho a la protección de la vida e integridad física y psíquica (19 $\left.\mathrm{N}^{\circ} 1\right)$, del derecho a la salud (19 $\left.\mathrm{N}^{\circ} 9\right)$ y del derecho a la igualdad (19 № 2). También se "suprime" antojadizamente -vista la revisión que a efectos de la protección del no nato hace el TC de la Convención Americana de Derechos Humanos y del Pacto de Derechos Civiles y Políticos- el catálogo de derechos que incluye ambos pactos y que, contrariamente a lo que sostiene el TC, han sido utilizados por los órganos de control del sistema americano y del sistema universal de derechos humanos, respectivamente, para fundar la legitimidad de algunos supuestos de interrupción de embarazo.

Por otra parte, se omiten consideraciones a la Convención sobre la eliminación de todas las formas de discriminación contra la Mujer (CEDAW por sus siglas en inglés), específicamente su artículo 16.e) que consagra los Ilamados derechos sexuales y reproductivos. Hay que mencionar al respecto que el Comité de la CEDAW, en tanto órgano de control de la Convención, viene desarrollando una nutrida jurisprudencia en materia de salud reproductiva. Parece altamente improbable que el TC no conozca tal jurisprudencia puesto que ésta ha sido ampliamente referida en los debates en torno a la eventual ratificación chilena del Protocolo Facultativo de la CEDAW. Como se sabe, el rechazo de esta ratificación por una parte importante de parlamentarios se funda en el hecho de que el Protocolo franquea una vía procesal para la presentación de peticiones individuales ante el Comité que encarnaría, según ellos, un peligro de revisión internacional de la legislación chilena que penaliza el aborto. Conviene precisar, en cualquier caso, que el peligro que se busca conjurar no es otro que el aumento de la efectividad de la CEDAW porque las violaciones de las que podría conocer el Comité son sólo aquellas que emanen de la infracción de la CEDAW, convención de la cual Chile ya es parte.

En el marco de la jurisprudencia del Comité de la CEDAW, puede destacarse la Recomendación General 24 Mujer y Salud (1999) que interpreta el alcance del artículo 12 de la CEDAW estableciendo que "la obligación de respetar los derechos exige que los Estados Partes se abstengan de poner trabas a las medidas adoptadas por la mujer para conseguir sus objetivos en materia de salud". Este texto agrega que "el acceso de la mujer a una adecuada atención médica tropieza también con otros obstáculos, como las leyes que penalizan ciertas intervenciones médicas que afectan exclusivamente a la mujer y castigan a las mujeres que se someten a dichas intervenciones" ${ }^{11}$. Evidentemente la referencia es a las normas que prohíben las interrupciones de embarazo y, todavía más, a las que las penalizan. Recuérdese que una consecuencia lógica del fallo del TC es que pueda entenderse que se configura un delito de aborto en caso de que una mujer acceda a una contraconcepción de emergencia, con lo que esta conducta pasa a engrosar la lista de

10 Un ejemplo paradigmático de esta clase de embarazos es el llamado embarazo ectópico.

11 CEDAW. Recomendación general 24 (20 periodo de sesiones, 1999), párrafo 14. 
conductas susceptibles de punición. Recuérdese, también, que la prohibición de distribución de estos compuestos alcanza solamente al sistema público de salud.

Y como si todo esto fuera poco, el TC sólo se hace cargo de la jurisprudencia comparada que apuntala su propia tesis $y$, sencillamente pasa por alto la jurisprudencia que la contradice. Particularmente, deja fuera la reciente sentencia de la Corte Constitucional colombiana que, en el marco de un control de constitucionalidad de las leyes colombianas que penalizan el aborto, desplegó un ejercicio de ponderación en que se triangulan las fuentes constitucionales internas, los tratados internacionales y el principio de proporcionalidad ${ }^{12}$. Así, la Corte Constitucional colombiana (en adelante la Corte) a diferencia del TC chileno, consideró que sí existen derechos de las mujeres involucrados, que el conflicto entre la protección del no nato y los derechos de las mujeres debe resolverse con aplicación del principio de proporcionalidad, y concluyó -sobre la base de ambos antecedentes- que la penalización absoluta del aborto implica una violación de este principio porque impone una carga desproporcionada para las mujeres en beneficio de la protección de los no natos.

El razonamiento de la Corte se construyó sobre el análisis de distintos supuestos de interrupción de embarazo (peligro para la vida de la madre, embarazo producto de violación o inseminación impuesta, malformación congénita del feto incompatible con la vida extrauterina del feto, embarazo no deseado) y la manera como éstos se relacionan con los derechos de las mujeres. Así, se estimó que los derechos a la vida y a la salud física y psíquica de las mujeres resultan vulnerados por la falta de atención médica en caso de que el embarazo ponga en peligro la vida de la madre o comprometa su salud. Asimismo, la Corte entendió que el derecho a la salud se conecta con el derecho al libre desarrollo de la personalidad y que ambos derechos ensamblados presuponen la autonomía en las decisiones relativas a la salud reproductiva, el derecho a planear la propia familia, el derecho a estar libre de interferencias en la toma de decisiones reproductivas y el derecho a estar libre de todas las formas de violencia y coerción que afecten la salud sexual y reproductiva. Es interesante notar que la falta de consagración expresa de los Ilamados derechos sexuales y reproductivos no ha sido óbice en el caso colombiano para establecer su protección. Lo mismo ha ocurrido en otros sistemas comparados y en el sistema internacional, en los cuales la garantía de tales derechos se ha derivado del derecho a la intimidad.

Además de lo anterior, la Corte consideró que se lesiona el derecho a la salud psíquica cuando a una mujer se le obliga a continuar un embarazo resultante de una violación o de una inseminación forzada porque se produce una doble victimización. Igualmente, estimó que cuando se impone a la mujer la continuación de un embarazo en que el feto sufre de una malformación congénita incompatible con la vida extrauterina, se viola el principio de proporcionalidad al imponerle a la mujer "sacrificios heroicos" o irrazonables ${ }^{13}$. Cabe mencionar que la Corte sostuvo respecto de este supuesto -como también lo han hecho antes el Comité de Derechos Humanos ${ }^{14}$ y el Comité

12 Véase Corte Constitucional, Sentencia C-355/06 de 10 de mayo de 2006.

13 Señala, en este sentido, que "en estos casos, el deber estatal de proteger la vida del nasciturus pierde peso, precisamente por estarse ante la situación de una vida inviable. De ahí que los derechos de la mujer prevalezcan y el legislador no pueda obligarla, acudiendo a la sanción penal, a llevar a término el embarazo de un feto que, según certificación médica, se encuentra en tales condiciones". íbid, p. 270.

14 Véase ZÚÑIGA, Y. Comentario al Dictamen del Comité de Derechos Humanos emitido a tenor del párrafo 4 del artículo 5 del Protocolo Facultativo del Pacto Internacional de Derechos Civiles y Políticos. Revista de Derecho de la Universidad Austral de Chile XIX (1), julio 2006, pp. 253-267. 
de la CEDAW - que tal imposición importa una infracción a la prohibición internacional de ser sometido a tortura y a penas o tratos crueles, inhumanos o degradantes ${ }^{15}$.

Como consecuencia de lo razonado, la Corte estimó que los siguientes casos no eran constitutivos de delito de aborto: a) cuando la continuación del embarazo constituya peligro para la vida o la salud de la mujer, certificado por un médico; b) cuando exista grave malformación del feto que haga inviable su vida, certificada por un médico; c) cuando el embarazo sea resultado de una conducta, debidamente denunciada, constitutiva de acceso carnal o acto sexual sin consentimiento, abusivo, o de inseminación artificial o de transferencia de óvulo fecundado no consentidas, o de incesto. Nótese que esta última hipótesis, es decir la entrega de la píldora en caso de violación, estaba expresamente prevista en el Decreto Supremo 48 impugnado.

La comparación entre ambos procedimientos argumentativos ahorra mayores comentarios al respecto.

Los dos fallos examinados simbolizan de manera diferente a las mujeres. El fallo del TC chileno reduce a las mujeres a meras matrices, conceptualizando la maternidad como una finalidad esencial inscrita en lo natural-biológico que escapa a la autonomía femenina y puede ser impuesta coercitivamente por el Estado. La Corte Constitucional colombiana, a la inversa, aplica los conceptos de intimidad, autonomía y dignidad humana en un sentido auténticamente liberal, depurándolos de toda ideología de género, y, en consecuencia, concibe a la maternidad como un plan de vida más, entregado a la autonomía de los individuos.

15 Habría que agregar que lo anterior también podría constituir un supuesto de violencia en los términos de la Convención de Belém do Pará. 